\title{
Las (sin)razones de la esperanza en Javier Muguerza e Immanuel Kant*
}

\author{
ROBERTO R. ARAMAYO \\ Instituto de Filosofía del CSIC, Madrid
}

\begin{abstract}
RESUMEN. Se pretende resaltar aquí la veta kantiana que atraviesa el pensamiento de Javier Muguerza. Este hilo conductor se pondría de manifiesto sin ir más lejos en las tres «Críticas» muguerzianas, a saber: Crítica de la razón analítica, Crítica de la razón dialógica y Crítica de la razón onírica. Pero también cabe detectarlo en el denominado «imperativo de la disidencia», con que Muguerza quiere actualizar las tres versiones del imperativo categórico kantiano y que le hace apostar, finalmente, por un blochiano primado de la utopía. En definitiva, todo ello acaba por invitarnos a replantear las célebres preguntas kantianas. Desde luego, a Javier Muguerza le interesan mucho más las cuestiones dejadas abiertas por Kant que sus respuestas, y hay que agradecerle que sepa traducirlas a las inquietudes filosóficas del presente.
\end{abstract}

ABSTRACT. The aim of this text is to highlight the Kantian influence upon the thought of Javier Muguerza, an influence which is evident in Muguerza's three «Critiques»: The Critique of Analytic Reason, The Critique of Dialogic Reason and The Critique of Oniric Reason. But Kant's influence can also be detected in the so-called «imperative of dissidence» with which Muguerza wants to render contemporary the three versions of the Kantian categorical imperative, and which also leads him to propose, in a Blochian manner, a primacy of utopia. In short, Muguerza invites us to pose again all the famous Kantian questions, even if he is more interested in those that Kant left open, than in those which he himself replied to. We have to be thankful to Muguerza for the translation of these questions into contemporary philosophical queries.

\footnotetext{
«La lucha por lo que demos en soñar como un mundo mejor no tendrá presumiblemente fin - ni la utopía tendrá nunca lugar si es que ha de hacer honor a su etimología-, puesto que siempre nos será dado imaginar un mundo mejor que el que nos haya tocado en suerte vivir» (Javier Muguerza, «Kant y el sueño de la razón», en La herencia ética de la Ilustración, p. 34).
}

* Este breve trabajo fue concebido inicialmente como una contribución a un volumen colectivo, titulado Disenso e incertidumbre, que Francisco Álvarez y quien esto suscribe queremos publicar alguna vez como homenaje a Javier Muguerza. El bicentenario kantiano me hace publicarlo ahora, cuando ya han transcurrido varios años desde su redacción. 
Hace ahora más de veinticinco años que Javier Muguerza publicó un libro, La razón sin esperanza ${ }^{1}$, que supuso todo un hito en el panorama filosófico español. Aquel mismo autor, que poco antes nos había familiarizado con «el giro lingüístico» gracias a esa excelente antología de textos titulada La concepción analítica de la filosofía ${ }^{2}$, reunía en esta obra diversos ensayos que transitaban por las distintas encrucijadas de la ética contemporánea. Para muchos de los que por entonces comenzábamos a estudiar filosofía, Javier Muguerza ofició como una especie de tutor que sabía guiar en la distancia nuestras lecturas, además de orientar nuestros intereses filosóficos, mediante sus escritos y conferencias, haciéndonos añorar lo que hubiera podido ser nuestra pobre vida universitaria si nuestras facultades hubiesen contado con profesores tan sugestivos como él. Andando el tiempo, justamente cuando aquel libro alcanzó su segunda edición, tuve la inmensa fortuna de trabar contacto personal con Javier y el privilegio de poder colaborar con él en algunas empresas académicas durante los últimos dieciocho años, cual sería el caso de la revista Isegoría.

\section{Las aporías morales de Kant}

Uno de los afanes que más he compartido con Javier Muguerza durante todo este tiempo es nuestro común empeño por darle vueltas al pensamiento kantiano y considerar a Kant un valioso interlocutor, al encontrarnos en una época donde se pretende hacer cierto balance de la modernidad. Ahí están para demostrar esta muguerziana «kantomanía» dos libros que fueron preparados con ocasión de sendos bicentenarios; me refiero al Kant después de Kant $^{3}$ y a La paz y el ideal cosmopolita de la Ilustración ${ }^{4}$. Pero, por supuesto, no es esta labor como coeditor literario lo que convierte a Javier Muguerza en un genuino «tornakantiano», por aplicarle aquella expresión que diera en acuñar Antonio Machado. Su interés por Kant va mucho más allá de lo que pueda imaginar el propio Javier Muguerza y ésa fue una de las razones (junto a otras de índole algo más personal) que me decidieron a dedicarle mi Antología de Kant ${ }^{5}$.

\footnotetext{
1 Cf. Javier Muguerza, La razón sin esperanza (Siete trabajos y un problema de ética), Madrid, Taurus, 1977 (2. ${ }^{\text {a }}$ ed. 1986).

2 Cf. Javier Muguerza (ed.), La concepción analítica de la filosofia, 2 vols., Madrid, Alianza Editorial, 1974 (cuya tercera edición sería publicada por Alianza Universidad en 1986).

3 Javier Muguerza y Roberto Rodríguez Aramayo (eds.), Kant después de Kant (En el bicentenario de la Crítica de la razón práctica), Madrid, Tecnos, 1989.

4 Roberto R. Aramayo, Javier Muguerza y Concha Roldán (eds.), La paz y el ideal cosmopolita de la Ilustración (A propósito del bicentenario de Hacia la paz perpetua de Kant), Madrid, Tecnos, 1996.

${ }_{5}$ Cf. Kant, Antología, edición de Roberto Rodríguez Aramayo, Barcelona, Ediciones Península (Textos Cardinales, 14), 1991. Antonio Pérez Quintana compartía con Javier esta dedicatoria y tam-
} 
Desde luego, esto tampoco significa que quiera presentar a Javier $\mathrm{Mu}$ guerza como un estudioso de los textos kantianos, cuya intención sea interpretar la letra del kantismo, pues no es ése afortunadamente su estilo ni cosa que vaya con su talante (aunque también esté muy lejos de menospreciar la paciente labor del scholarship y le parezca una tarea necesaria). La simpatía que Kant suscita en Javier Muguerza marcha por otros derroteros y tiene «bastante más que ver con la manera como Kant planteaba los problemas que con las soluciones que, a veces, arbitró para ellos. Y digo a veces porque, de sus honestos planteamientos, no parece otras veces que se siga sino la imposibilidad de dar esos problemas por zanjados o, si lo preferimos expresar así, la obligación de reconocerlos irresueltos y quién sabe si, en definitiva, irresolubles» 6 .

A Javier Muguerza le interesan, sobre todo, las aporías morales planteadas por Kant a lo largo de sus escritos, esto es, como él mismo acaba de señalar, el honrado planteamiento kantiano de ciertas cuestiones éticas que no podemos eludir y a las que siempre deberemos continuar enfrentándonos, a pesar de que dichos problemas puedan acabar por mostrarse del todo irresolubles y nos dejen sumidos en la más absoluta perplejidad. Javier Muguer$\mathrm{za}$, hay que insistir en ello, se interesa sobremanera «por los problemas que Kant se planteó, pero no necesariamente por las soluciones que el propio Kant les diera ${ }^{7}$. Pues lo que le importa en verdad a la ética es el reflexionar acerca de los dilemas morales y no tanto apostar por uno u otro de sus cuernos. Lo que cuenta realmente para la filosofía moral es el itinerario y no tanto la meta o destino a los que cupiese arribar por senderos bien señalizados, habida cuenta de que - como dijo el poeta - en realidad la ruta no está previamente trazada y sólo se hace camino al andar.

Por ello, aun cuando sospechemos que nunca llegaremos a solventar de un modo plenamente satisfactorio los problemas plateados por la ética, esa sospecha sólo ha de servir para redoblar nuestros esfuerzos y aceptar con mayor ímpetu el enorme desafio de afrontar cabalmente su examen, sin sucumbir jamás a la fácil tentación de soslayarlos, aunque sí nos esté permitido algo tan elemental como el tomarnos un descanso de vez en cuando, para reponer fuerzas antes de reanudar nuestra marcha. «Ya que no para mayores provechos - advertía Javier Muguerza en el prólogo a La razón sin esperanza -, la filosofía analítica debería haber servido por lo menos para hacernos desconfiar de que con los problemas filosóficos quepa aspirar a tanto como resolverlos. Mas conste que tampoco me entusiasma la demasiado cómoda terapia, no menos analítica, que nos invita a contentarnos con

bién la de mi libro Immanuel Kant. La utopía moral como emancipación del azar (Madrid, Edaf, 2001).

6 Cf. Javier Muguerza, «Por un Kant aporético», prólogo a Roberto R. Aramayo, Crítica de la razón ucrónica (Estudios en torno a las aporías morales de Kant), Madrid, Tecnos, 1992, p. 13.

7 Cf. Javier Muguerza, La razón sin esperanza, Madrid, Taurus, 1986, p. 43. 
disolverlos. Si de mí dependiera, yo diría que a lo más que podemos aspirar $-\mathrm{y}$ con lo menos que nos podemos contentar- es a absolvernos de seguirlos tratando después de haber bregado honradamente con los mismos hasta donde nos lo hayan permitido nuestras fuerzas» ${ }^{8}$.

\section{El callejón de la ética}

Recreando una metáfora de cuño wittgensteiniano, Javier Muguerza nos recuerda que las Investigaciones filosóficas daban en comparar a la lógica con una ciudad. Dicha ciudad «estaría constituida - nos relata Javier Muguerza - por un conjunto de calles, avenidas y plazas; tantas y de tan variado trazado, cuantas el hombre haya podido necesitar a lo largo de su historia para llevar a cabo esa compleja actividad que conocemos por "razonar". Si contemplamos la ciudad a vista de pájaro, lo que más llama la atención es un conjunto residencial, el barrio de las ciencias formales o empíricas. Se trata del barrio más elegante de la Ciudad del Logos, donde se realizan los grandes negocios del razonamiento y donde se halla enclavado el comercio lógico más floreciente. Pero, por mucho que ese barrio requiera de atención especial por parte del ayuntamiento, no hay la menor disculpa para tener convertido al resto de la ciudad en una cochambre. Y eso es, en cierto modo, lo que ha venido a suceder con ciertos tipos de argumentación, como la argumentación moral, a la que correspondería una calleja oscura y mal pavimentada, aunque, eso sí, bastante céntrica y transitada a pesar de su mal estado; de ahí el riesgo de accidentes que continuamente amenaza a la teorización acerca de la praxis humana» ${ }^{9}$.

Pues bien, tengo la impresión de que, a través de sus textos y de una manera un tanto subrepticia, Javier Muguerza ha postulado muchas veces a Kant como un alcalde idóneo para gobernar la ciudad recién descrita y equilibrar así ese trato desigual que se habría dispensado a los distintos núcleos urbanos por parte de sus antiguos regidores, tan proclives a olvidarse del barrio de la ética. Ciertamente, si Kant lograra situarse a la cabeza del ayuntamiento, a buen seguro que los callejones éticos no se verían tan descuidados, pues allí es donde gustaría de residir el primer edil y fijaría su sede la nueva corporación municipal, toda vez que «a Kant no le preocupaba únicamente averiguar qué es lo que el hombre puède conocer, sino también qué debe hacer, qué le es dado esperar y qué es, en suma, el hombre» ${ }^{10}$.

Ahora bien, a Kant no le importaría en absoluto que dentro del mencionado barrio hubiese más de una calle sin salida o que su trazado fuese más bien laberíntico, pues era muy consciente de que la reflexión ética no puede

\footnotetext{
${ }^{8}$ Cf. Javier Muguerza, op. cit., p. 13.

${ }^{9}$ Cf. op. cit., p. 52.

${ }^{10}$ Cf. op. cit., p. 34.
} 
pretender ponerse a deambular por amplias y populosas avenidas, al tener que producirse dicha deliberación en el patio interior de nuestra propia conciencia moral. Pero esa íntima convicción tampoco le impidió preocuparse por alumbrar lo mejor posible los tortuosos callejones del fuero interno, cuyos dominios quiso limpiar de todo cuanto le fuese ajeno, aspirando incluso a emanciparlo del propio azar, por considerar que todo cuanto dependiera de la suerte no podía tener cabida en una morada donde uno sólo debe contar consigo mismo, sin atender a ninguna otra instancia o piedra de toque. Su principal preocupación consistió en encontrar un hilo de Ariadna que pudiera servir para orientarnos dentro del intrincado laberinto configurado por las encrucijadas morales. Ni siquiera se propuso establecer algo parecido a un código de la circulación y, bien al contrario, quiso involucrar a todos los vecinos del barrio ético en esa tarea, invitándolos a inventarse de forma personalizada sus propias reglas en cada momento.

El formalismo ético kantiano sólo pretendió acuñar una nueva fórmula (aunque la misma cuente con tres expresiones diferentes, como es bien sabido) que debe ser aplicada por cualquiera de sus usuarios con mayor o menor fortuna ${ }^{11}$. Sin embargo, si echamos un vistazo bajo el pavimento que recubre aquellos céntricos callejones para inspeccionar sus alcantarillas, nos encontraremos con lo que ha convertido a Kant en un clásico inexcusable de la modernidad. Allí descubriremos las aporías morales en que suelen desembocar sus refinados planteamientos éticos. Y, a mi modo de ver, ese perspicaz lector de Immanuel Kant que se llama Javier Muguerza ha sabido resucitar esas aporías, haciéndoles cobrar mediante sus propios trabajos una inusitada vigencia. Veamos hasta dónde llega esta presunta «kantomanía» que doy en atribuir a Javier Muguerza.

\section{Las tres «Críticas» de Javier Muguerza}

Puestos a trazar ciertos paralelismos entre Javier Muguerza e Immanuel Kant, habría que comenzar por advertir que al primero le divierte presentar sus propias publicaciones bajo el kantianísimo rótulo de «Críticas». Cuando menos, así decide hacerlo en una entrevista firmada por María Herrera y Carlos Pereda, donde Javier Muguerza resume los contenidos de su libro La razón sin esperanza en estos términos: «allí abordaba una discusión de la teoría de la razón práctica en el contexto de la filosofía moral de inspiración

\footnotetext{
1 Sobre la escasa fortuna que tuvo el propio Kant en este menester, cuando quiso aplicar alguna vez al terreno de lo concreto sus admirables presupuestos teóricos, versa un trabajo mío titulado: «El dilema kantiano entre antropología y ética (¿Acaso representan los dictámenes jurídico-penales de Kant una concreción casuística del formalismo ético?)», en Roberto R. Aramayo y F. Oncina (eds.), Ética y antropología: un dilema kantiano, Granada, Comares, 1999, pp. 23-41. El balance difícilmente podría resultar más desolador, dado que invariablemente se atenta contra la sensatez y el sentido común.
} 
analítica o, si no resulta pretencioso decirlo así, una crítica de la ética analítica entendida como una "crítica de la razón práctica" en tal contexto. En este sentido, procedía a discutir con las etapas y corrientes más significativas de aquella ética, como el "emotivismo", el "prescriptivismo", la ética de las "buenas razones", etcétera. Y pretendía hacer todo eso metiéndome "en" la ética analítica, al menos tanto como "con" ella o "contra" ella, pues nunca me ha gustado eso de estar de vuelta sin haberse tomado uno la molestia de estar antes de ida» 12 .

Sólo unas líneas más abajo Javier Muguerza contesta lo siguiente respecto a su otro gran libro, Desde la perplejidad ${ }^{13}$ : «esta obra prosigue la reflexión en torno a la razón práctica pero en un contexto ya postanalítico y, muy concretamente, en discusión con la hermenéutica y, sobre todo, la teoría crítica habermasiana, es decir, en discusión con la ética comunicativa. La parte central del libro, que es un libro en sí misma, se titula precisamente "Para una crítica de la razón dialógica". Y pretende, como la anterior crítica de la ética analítica, ser honesta para con la ética comunicativa, esto es, hacerse cargo por igual de lo que entiendo que son sus posibilidades y sus límites».

Como no podía ser menos, a estas dos «Críticas», la Crítica de la razón analítica y la Crítica de la razón dialógica, había de seguirle una tercera. Pues bien, ese tercer libro ya está en camino y, esbozando una leve sonrisa, me voy a permitir la pequeña broma de bautizarla como Crítica de la razón onírica, invocando para ello una razón tan espuria como que la palabra «sueño» aparezca por dos veces en su título. Esta obra promete ser la más kantiana de las escritas por Javier Muguerza (de hecho es la que ha inspirado este lúdico divertimento) y se titula Sueños de la razón, razones de los sueños ${ }^{14}$.

Quizá no se hayan dado cuenta, pero Javier Muguerza parece observar una escrupulosa cadencia -impropia de alguien tan poco puntual como es él- en la preparación de sus libros. La razón sin esperanza data de 1977, Desde la perplejidad estaba listo en 1987, aunque diversos avatares editoriales retrasaron su aparición todo un trienio y su libro Sueños de la razón está proyectado desde 1997. El índice de la progresión aritmética es bastante obvio, ¿verdad? Los distintos tramos ocupan una década. Se diría que Javier Muguerza quisiera emular en esta periodización al bueno de Kant, quien empleó diez largos años en concebir su primera Crítica y no publicó nada desde la Dissertatio, fechada en 1770, hasta que apareció su Crítica de la razón pura un decenio después.

${ }^{12}$ Cf. María Herrera y Carlos Pereda, «Entrevista con Javier Muguerza», Theoria, núm. 2, Universidad Autónoma Nacional de México, 1995. La cursiva es mía.

${ }_{13}$ Cf. Javier Muguerza, Desde la perplejidad (Ensayos sobre la ética, la razón y el diálogo), México/Madrid/Buenos Aires, Fondo de Cultura Económica, 1990 (2.. ed. 1995).

${ }_{14}$ Cf. Javier Muguerza, Sueños de la razón, razones de los sueños, Madrid, Trotta (en preparación). 
Claro está que a Javier Muguerza no se le puede aplicar aquello de la «década del silencio», comó se ha llamado a esos diez años en que Kant gestó laboriosamente su sistema crítico (al igual que tampoco vale atribuirle rasgos tan específicamente kantianos como la puntualidad, el ascetismo o lo de no viajar), porque, durante los dos lustros que median entre una y otra de sus obras, Javier no para de dar conferencias en todas partes, escribe innumerables prólogos y otras tantas recensiones, publica un sinfín de artículos en las más variopintas revistas o prepara volúmenes colectivos destinados a cruzar nuestras fronteras ${ }^{15}$.

\section{El imperativo de la disidencia}

Pero los paralelismos no se agotan con lo dicho hasta el momento, ni muchísimo menos. Pues, aparte de los grandes libros homologables a las Críticas (por la relevancia que tienen dentro del pensamiento de su autor), nos encontramos, asimismo, con un texto cuyo equivalente sería la Fundamentación, toda vez que allí se acuña el imperativo en donde se fundamenta la ética tal como es concebida por Javier Muguerza. Estoy pensando, como cualquiera de sus lectores habrá adivinado, en La alternativa del disenso ${ }^{16} \mathrm{y}$ su ya célebre «imperativo de la disidencia». Este sugestivo texto aparecerá, dentro de muy poco, reformulado y enriquecido con otro trabajo que lleva por título «Primado de la autonomía: ¿Quiénes trazan los lindes del coto vedado?» ${ }^{17}$, dando lugar a un libro que se tituló Ética, disenso y derechos humanos ${ }^{18}$, cuyo sitio en la obra de Javier Muguerza podría ser comparado con el que ocupan los Principios metafísicos de la teoría del derecho dentro del pensamiento kantiano. Las reflexiones vertidas en esa Fundamentación de la ética muguerziana que supone su Alternativa del disenso han ido decantándose con el paso del tiempo y ahora Javier Muguerza parece anunciar lo que, dentro de mi lúdico paralelismo, podría oficiar como un correlato de la kantiana Metafísica de las costumbres. Esta obra, titulada en princi-

${ }_{15}$ Mientras prepara su tercera «Crítica» Javier Muguerza ha entregado a la imprenta, por ejemplo, su Ethik der Ungewissheit (übersetzung von Ruth Zimmerling), Freiburg-München, Alber Verlag, 1990, y el colectivo a su cuidado que lleva por título Ethik der Unbehagen (25. Jahre ethische Diskussion in Spanien) (übersetzung von Ruth Zimmerling), Freiburg-München, Alber Verlag, 1991.

${ }^{16}$ Cf. Javier Muguerza y otros autores, El fundamento de los derechos humanos, edición preparada por Gregorio Peces-Barba Martínez, Madrid, Debate, 1989, pp. 19-56. Como es bien sabido, «La alternativa del disenso (En torno a la fundamentación ética de los derechos humanos)» fue auspiciada por The Tanner Lectures on Human Values.

${ }_{17}$ Que se halla recogido en el volumen colectivo: R. R. Aramayo, J. Muguerza y A. Valdecantos (comp.), El individuo y la historia (Antinomias de la herencia moderna), Barcelona, Paidós, 1995, pp. 133-154.

${ }_{18}$ Cf. Javier Muguerza, Ética, disenso y derechos humanos (En conversación con Ernesto Garzón Valdés), Madrid, Arjés, 1997. 
pio Decir que no ${ }^{19}$, también fue proyectada, curiosamente, justo en el bicentenario de la kantiana Doctrina de la virtud (1797).

Imperativo de la disidencia es el nombre con que Javier Muguerza decide referirse a una de las tres formulaciones del imperativo categórico kantiano, concretamente aquella que reza: «Obra de tal modo que uses a la humanidad, tanto en tu persona como en la persona de cualquier otro, siempre al mismo tiempo como fin y nunca simplemente como medio» ${ }^{20}$. Su argumentación para escoger este apodo en lugar de cualquier otro es el siguiente: «He llamado a dicho imperativo el imperativo de la disidencia, por entender que - a diferencia del principio de universalización, desde el que se pretendía fundamentar la adhesión a valores como la dignidad, la libertad o la igualdad-, lo que ese imperativo habría de fundamentar es más bien la posibilidad de decir "no" a situaciones en las que prevalecen la indignidad, la falta de libertad o la desigualdad» ${ }^{21}$.

¿Cuál es la ventaja de cargar las tintas en esta reformulación del imperativo kantiano? Dejemos que sea el propio Javier Muguerza quien conteste: «Para decirlo en dos palabras, se trataría de preguntarnos si - tras tanta insistencia en el consenso, fáctico o contrafáctico, acerca de los derechos humanos - no extraeremos más provecho de un intento de "fundamentación" desde el disenso, esto es, de un intento de fundamentación "negativa" o disensual de los derechos humanos, a la que llamaré "la alternativa del disenso". Desde luego, esta idea no parece del todo descabellada si reparamos en que la fenomenología histórica de la lucha política por los derechos humanos, bajo cualquiera de sus modalidades conocidas, parece haber tenido algo que ver con el disenso de individuos o grupos de individuos respecto de un consenso antecedente - de ordinario plasmado en la legislación vigente - que les negaba de un modo $\mathbf{u}$ otro su pretendida condición de sujetos de tales derechos» ${ }^{22}$. La moraleja que se desprendería de dicho imperativo muguerziano, al autorizarnos moralmente a decir que no ante un derecho injusto, por muy consensuada que pueda estar esa injusticia, sería la de que los protagonistas del derecho debemos serlo todos ${ }^{23}$.

${ }^{19}$ Cf. Javier Muguerza, Decir que no (Ensayo sobre la relevancia ética de la negación), Madrid, Trotta (en preparación). He aquí los capítulos que conformarán esta obra: 1. El precio de la libertad (Una meditación acerca de la ley y la desobediencia). 2. De la conciencia al discurso: ${ }_{\text {Un }}$ Un viaje de ida y vuelta? 3. Más allá del universalismo y el contextualismo ético. 4. Sobre el imperativo de la disidencia: Objeciones y respuestas. 5. ¿Qué es el individualismo ético? 6. En torno a la idea de razón pública. 7. Decir que sí.

${ }^{20} \mathrm{Cf}$. I. Kant, Fundamentación para una metafisica de las costumbres, edición de Roberto $\mathrm{R}$. Aramayo, Madrid, Alianza Editorial, 2002, p. 116.

${ }^{21}$ Cf. Javier Muguerza, «La alternativa del disenso», en El fundamento de los derechos humanos, op. cit., p. 43.

${ }_{22}$ Cf. op. cit., pp. 43-44.

${ }^{23}$ Cf. op. cit., p. 55 . 


\section{La tolerancia y el disidente muguerziano ${ }^{24}$}

Según creo, la mayor dificultad que debe resolver el imperativo de la disidencia consistiría en llegar a definir con claridad los rasgos característicos del buen disidente, para no caer en la peligrosa tentación de investir como acto moral a toda disidencia por el mero hecho de serlo. Y, en este orden de cosas, el principio de universalización constituye un primer criterio elemental e insustituible. Como es natural, el disidente del que nos habla Javier Muguerza no tiene vocación de free rider. Que los demás acaten las normas, ya sean éstas éticas o jurídicas, mientras que uno logra esquivarlas al mismo tiempo, constituye una situación óptima para la cosmovisión del «gorrón» de turno. Mas no es ésa la mentalidad propia del buen disidente, quien, en vez de buscar alguna rentabilidad personal con su postura, suele tener que apechar con unas consecuencias muy poco provechosas para él, como es el caso del insumiso que acaba en la cárcel por negarse a cumplir con un servicio social militar carente de sentido alguno.

A quien practica la disidencia de corte muguerziano le ocurre lo que al verdadero amante del juego: no soporta las trampas, a las que odia cordialmente, pues lo que busca es demostrarse a sí mismo su dominio del juego en cuestión y que su astucia puede invocar con éxito a la fortuna. No hay nadie más opuesto a un tahur que quien disfrute de verdad con los naipes y nada resulta más ajeno al espíritu del «aprovechategui» que la disidencia muguerziana, la cual, en último término, sólo quiere denunciar las trampas que cabe detectar en determinadas reglas de juego. Tal como ha escrito Tugendhat, las reglas estipuladas en los juegos de azar «son siempre justas y no benefician a un participante frente a otro, por el simple motivo de que nadie querría participar en un juego con semejantes reglas» ${ }^{25}$. Ésa es la razón que inhibe al disidente a participar en el juego y a manifestar su disenso, el no aceptar aquello que la voz de su conciencia le descubre como una situación injusta.

Ésa es la razón que inhibe al disidente a participar en el juego y a manifestar su disenso, el no aceptar aquello que la voz de su conciencia le descubre como una situación injusta. Su mayor deseo es establecer unas reglas de juego que sean justas y resulten equitativas para todos los participantes. Es claro que no pretende constituir una excepción a la norma, sino que tiende a modificar ésta, siendo su disenso lo que acaba por dinamizar la revisión y actualización de las pautas morales o jurídicas. Cuando el disidente lucha

\footnotetext{
${ }^{24}$ Este apartado rentabiliza mi trabajo «La pseudoantinomia entre autonomía y universalidad: un diálogo con Javier Muguerza y su imperativo de la disidencia» (incluido en El individuo y la historia, op. cit., pp. 155 y ss.), al que remito para una mejor comprensión de lo apuntado someramente aquí.

${ }^{25}$ Cf. Ernst Tugendhat, Problemas de la Ética, versión castellana de Jorge Vigil, Barcelona, Crítica, 1988, p. 86.
} 
contra la indignidad y aboga con el disenso por su desaparición, lo hace con el afán de universalizar su punto de vista. El disidente genuinamente moral no puede renunciar a la pretensión de universalizar sus anhelos. Bajo esa premisa el insumiso (al menos el tipo de insumiso que me interesa traer aquí a colación) no querría librarse sin más de hacer la mili o verse absuelto de perder su tiempo realizando un servicio social «expiatorio», sino que le gustaría ver instaurado un orden social donde no tenga cabida el servicio militar obligatorio.

Sin contar con esa universalizabilidad su disenso no tendría ninguna significación ética. Pero aquello que caracteriza y define realmente al disenso muguerziano es otra cosa: el ejercicio de una sana e incontestable tolerancia, que viene a poner en su sitio los excesos del rigorismo kantiano. Desde la perspectiva defendida por Javier Muguerza, «no se desprende, pues no faltaba más, que un individuo pueda imponer a una comunidad la adopción de un acuerdo que requiera de la decisión colectiva, sino sólo que el individuo se halla legitimado para desobedecer cualquier acuerdo o decisión colectiva que atente - según el dictado de su conciencia - contra la condición humana» ${ }^{26}$. He aquí la principal virtud esgrimida por el disidente muguerziano. Por supuesto que propende a universalizar sus afanes (de no ser así, se haría sospechoso de perseguir un mero beneficio particular), pero contando con el provechoso y recomendable límite de la tolerancia, pues no pretende imponer sus criterios a nadie, sino que se contenta justo con lo contrario, es decir, que no se le haga suscribir algo intolerable para su conciencia.

Lejos de invocar la razón de la fuerza, quien así disiente sólo quiere apelar a la fuerza de la razón; ciertamente, no pretende vencer, sino convencer a los demás con el testimonio vivo de su propia conducta, cuyo rasgo más definitorio sería, como digo, un fervoroso culto a la tolerancia. Ésta es, a mi juicio, la mejor aportación del planteamiento muguerziano, que propende a corregir las posibles desviaciones del rigorista universalismo kantiano con el ejercicio de la tolerancia. «Está claro - apunta Javier Muguerza - que el buen disenso sólo autoriza al disidente a rehusar hacer suya la voluntad de los demás cuando ésta contradice los dictados de su conciencia, pero no le autoriza en cambio a imponer por la fuerza a los demás su propia voluntad» ${ }^{27}$.

No es mal criterio este de la tolerancia y resulta tremendamente oportuno resucitarlo ahora, en los tiempos que corren. Si algo necesitan estas postrimerías del milenio, tan asediadas por los más variopintos fanatismos, es precisamente una cruzada contra toda clase de intolerencia. Una contienda en donde viene a prestar sus armas ese imperativo de la disidencia forjado por

\footnotetext{
${ }^{26}$ Cf. Javier Muguerza, «La obediencia al Derecho y el imperativo de la disidencia (Una intrusión en un debate)", Sistema, núm. 70, 1986, p. 39.

${ }^{27} \mathrm{Cf}$. Javier Muguerza, «Primado de la autonomía: ¿Quiénes trazan los lindes del coto vedado?», en El individuo y la historia, op. cit., p. 144.
} 
Javier Muguerza ${ }^{28}$ : «La negativa a atentar contra la dignidad humana, atentado que en nuestro siglo adquirió el rango de un "imperativo inmoral" de alcance planetario, bien podría merecer el nombre - con la finalidad de distinguirlo de esos otros principios o imperativos que eran el de la universalización y el de la autodeterminación - de principio o imperativo de la disidencia. El tenso equilibrio entre universalidad y autonomía que mantenían aquellos principios se decantaría en él del lado de la autonomía, la autonomía para el disenso frente a la universalidad de cualquier consenso que en conciencia - y no hay otra conciencia que la individual - juzquemos inmoral. La autonomía que - heredera del "individualismo ético" de Kant- ha de manifestarse hoy, ante todo, como capacidad de negación ${ }^{29}$.

\section{Javier Muguerza como «traductor» del mejor Kant}

Ahora bien, al igual que hiciera Kant en su momento, también Javier Muguerza se ve obligado a dar un paso previo antes de forjar ese idiosincrásico imperativo moral en que fundamenta toda su teoría ética y procede a reformular cabalmente la tercera de las antinomias kantianas, traduciendo a un lenguaje tan actual como comprensible la dicotomía básica del criticismo. En esta traducción conceptual de los términos kantianos, la distinción entre fenómeno y noúmeno queda canjeada por dos perspectivas diferentes que no pueden intercambiarse sin pagar un alto precio, a saber, el punto de vista que cabe aplicar a los demás y aquel otro que sólo nos es dado tener respecto de nosotros mismos.

El comportamiento ajeno sí puede ser enfocado bajo la óptica del necesario determinismo causal en busca de alguna explicación, pero esa lente nunca podrá servir para enjuiciar la propia conducta, salvo que nos hallemos dispuestos a dejar de ser sujetos morales. «Cuando nosotros describimos las acciones de nuestros semejantes no es del todo ilegítimo que lo hagamos en términos causales, explicándonos su conducta en virtud de los condicionamientos naturales o sociales que les llevan a comportarse de tal o cual manera. La atribución de tales relaciones de causa-efecto pudiera resultar en ocasiones discutible, pero lo cierto es que se acostumbra a llevarla a cabo. Y así es como decimos, por ejemplo, que "dadas las circunstancias, Fulano no podía actuar de otra manera". Así es como hablamos de Fulano en tercera persona. ¿Pero podríamos hacer otro tanto cuando cada uno de nosotros habla en nombre propio y se refiere a sí mismo en primera persona? Bien miradas las cosas, hablar así sería sólo una excusa para eludir nuestra responsabilidad

\footnotetext{
${ }^{28}$ Cf. el juicio crítico que cierra mi edición de Voltaire, Tratado sobre la tolerancia, estudio y notas por Roberto R. Aramayo, Madrid, Santillana («Filosofía hoy»), 1997, pp. 104-105.

${ }^{29}$ Cf. Javier Muguerza, «Kant y el sueño de la razón», en Carlos Thiebaut (dir.), La herencia ética de la Ilustración, Barcelona, Crítica, 1991, p. 35.
} 
moral, la responsabilidad que a todos nos alcanza por nuestros propios actos. Cuando diga "no pude actuar de otra manera" o "las circunstancias me obligaron a actuar como lo hice", estaría sencillamente dimitiendo de mi condición de persona, para pasar a concebirme como una cosa más, sometida como el resto de las cosas a la forzosa ley de la causalidad. O, con otra palabras, estaría renunciando a la humana carga de ser dueño de mis actos» ${ }^{30}$.

Con esta reformulación del problema planteado por Kant en la más famosa de sus antinomias, Javier Muguerza nos demuestra cómo cabe «traducir» a un autor clásico para rescatar cuanto haya de valioso bajo una letra obsoleta. Estás líneas han sido entresacadas de un artículo que se titula «Kant y el sueño de la razón», donde Javier Muguerza examina una tras otra las célebres preguntas kantianas, preguntándose a su vez cómo podríamos administrar hoy en día los legados éticos de la Ilustración. Dicho escrito está llamado a constituir el primer capítulo de lo que más arriba di en llamar su Crítica de la razón onírica, un libro al que su autor prefiere poner el título de Sueños de la razón, razones de los sueños.

En esta obra Javier Muguerza mantiene un fructífero diálogo con Kant, llegando incluso a comentar con cierto detalle alguno de los textos kantianos que más han llamado su atención, cual sería el caso del opúsculo conocido como El conflicto de las Facultades, cuyo pormenorizado análisis ocupa todo un capítulo - el cuarto - del mencionado ensayo de Javier Muguerza. Este apartado, que se titula «La indisciplina del espíritu crítico (Una aproximación filosófica al problema de la educación)» ${ }^{31}$ y donde se realza el papel que deberían jugar las humanidades en general - así como la filosofía en particular - dentro la pedagogía contemporánea, viene a cerrarse con el siguiente párrafo: «A través de un comentario de texto, este mío ha tratado, en la modesta medida de sus posibilidades, de ejecutar una de aquellas operaciones de rescate de un pasado que la historia se habría encargado, como suele, de frustrar. Y a partir de dicho intento de recuperación, ha tratado no menos, aun si con no menor modestia, de sugerir alguna vía que nos permita la imaginación de un futuro mejor, asimismo expuesto, cómo no, a una más que probable frustración histórica. Es cierto que, hoy por hoy, nada habría de importarnos tanto como nuestro presente, pues a él le corresponde delimitar dónde estamos y, en definitiva, desvelar lo que somos. Pero la atención al presente no nos impide, e incluso nos exige, preguntarnos de dónde venimos y adónde queremos o no queremos ni debiéramos querer ir. Después de todo, como diría el poeta, ni el ayer ni el mañana están escritos y sólo nosotros los podemos escribir o, mejor dicho, tenemos que escribirlos para poder vivir de veras el presente» ${ }^{32}$.

${ }^{30}$ Cf. op. cit., pp. 19-20.

${ }^{31}$ Generosamente Javier Muguerza me permitió reproducir este trabajo como epílogo a mi edición castellana de I. Kant, El conflicto de las Facultades, Madrid, Alianza Editorial, 2003.

${ }^{32}$ Cf. op. cit., p. 233. 
Es esta íntima convicción la que le permite a Javier Muguerza oficiar como un magnífico «traductor» del mejor Kant ${ }^{33}$ e invitarnos con ello a una lectura crítica de sus textos (ahora me refiero a los de ambos), no desde luego con la idea de interpretarlos escolarmente, sino para enraizar en ellos nuestra meditación personal sobre los problemas que allí se desgranan. Podrían multiplicarse los ejemplos, pero me conformaré con añadir una última muestra. En el segundo capítulo de los Sueños de la razón ${ }^{34}$, Javier Muguerza rinde homenaje a una metáfora vertida por Kant en su Metafísica de las costumbres y que ha sido muy apreciada por los cultivadores de la filosofía moral. Se trata del tribunal de la conciencia. Tras recrear el símil kantiano, advirtiendo de sus posibles limitaciones psico-socio-históricas, Javier Muguerza nos brinda una sugerente reflexión que transciende los muros de la ética y atraviesa los de la filosofía del derecho. Su conclusión es que, tanto en el ámbito moral como dentro del terreno jurídico, existe una magistratura suprema cuyo dictamen resulta inapelable y no puede verse revisado por ninguna otra instancia: ésta no es otra que la sentencia de nuestro fuero interno: «Aun cuando nadie pueda nunca tener la seguridad de estar haciendo lo que moralmente debiera, hacer lo que en conciencia cree que debe hacer es lo más lejos que un individuo puede ir cuando pretende cumplir con su deber moral, por lo que, en lo tocante a tal deber, no alcanzo a divisar otra instancia por encima de la propia conciencia individual» ${ }^{35}$.

\section{La sinrazón de la esperanza, o el primado del pensamiento utópico}

Huelga señalar que Javier Muguerza desborda con creces esta torpe caricatura, empecinada en hacerle pasar por un impenitente «tornakantiano», y resulta ocioso, asimismo, insistir en que sus libros van mucho más allá de cuanto aquí se ha señalado (al igual que su personalidad es mucho más compleja, rica e interesante que la del filósofo de Königsberg). Pero no es menos cierto

${ }^{33}$ A Javier Muguerza le interesa sobre todo el Kant moralista, mucho más que aquel filósofo de la historia y ese reputado epistemólogo que también fue. De hecho, para dejar clara esta preferencia, decidió popularizar el asombroso hallazgo de un investigador cordialmente ignorado por los KantStudien y que, para colmo de males, habría extraviado los documentos que acreditaban su relato. Según este desconocido autor, las obras de Kant habrían sido escritas realmente por tres hermanos que compartían el apellido, mas no las mismas inquietudes. David, el mayor (que había sido criado en Escocia y le hizo creer a su hermanito más pequeño que la saga familiar procedía de allí) se habría encargado de los escritos epistemológicos, incluyendo buena parte de la Crítica de la razón pura, mientras el benjamín, Georg Wilhelm Friedrich (que se parecía muchísimo a Hegel), sería el auténtico responsable del Opus postumum, gran parte de la Crítica del discernimiento y casi todos los opúsculos dedicados a filosofar sobre la historia; de suerte que Immanuel, el mediano, sólo habría redactado propiamente la Fundamentación, la Metafísica de las costumbres y la Crítica de la razón práctica (cf. Javier Muguerza, Desde la perplejidad, op. cit., pp. 677-678).

${ }^{34} \mathrm{Cf}$. «El tribunal de la conciencia y la conciencia del tribunal (Una reflexión ético-jurídica sobre la ley y la conciencia)», Doxa, vol. II, núm. 15, 1994, pp. 535-559.

${ }^{35}$ Cf. ibid., p. 546. 
que su pensamiento cuenta con una gran veta kantiana e incluso que ha ido explotando cada vez más este filón con el paso del tiempo, tal como demuestra un somero vistazo a sus últimos escritos o a las publicaciones que actualmente prepara. No en vano, como ya ha quedado dicho, se propone bautizar a su próximo libro con el rótulo de Sueños de la razón, razones de los suenos, lo cual nos recuerda mucho el título de un escrito kantiano que Javier Muguerza citaba con fruición en La razón sin esperanza, donde al finalizar el primer trabajo transcribía estas líneas de los Sueños de un visionario, esclarecidos mediante los sueños de la metafisica: «La balanza de la razón no es, en efecto, absolutamente imparcial, y uno de sus brazos - el que ostenta la inscripción «esperanza de futuro»- se beneficia de una ventaja mecánica merced a la cual incluso las más ligeras consideraciones depositadas en el correspondiente platillo consiguen vencer a las especulaciones de mayor peso intrínseco depositadas en el otro. Ésta es la única inexactitud que no creo me sea dado corregir y que, a decir verdad, tampoco quiero enmendar en modo alguno» ${ }^{36}$.

Si hay algo en lo que Javier Muguerza coincida enteramente con Kant es esta irrenunciable debilidad por la esperanza en el futuro. Pues ambos autores comparten «la incapacidad de pensar que la injusticia que domina la historia sea definitiva» ${ }^{37}$. Por muchas que sean las razones y evidencias en sentido contrario, tanto Kant como Javier Muguerza no dudarán en desequilibrar el fiel de la balanza mediante un sinfín de sinrazones, con tal de que finalmente acabe por inclinarse hacia la dirección correcta, es decir, en favor del horizonte utópico soñado por su razón y su conciencia moral.

Ese mundo mejor que anticipamos - nos dice Javier Muguerza glosando a Bloch - y que todavía no ha llegado a ser no es otro que el mundo tal y como pensamos que debiera ser. Lo que Bloch llama la "función utópica" de la esperanza es la anticipación de dicho mundo que se abre paso por los oscuros vericuetos de lo aún-no-consciente o "preconsciente", a no confundir con el inconsciente freudiano o ya no consciente, puesto que - a diferencia de él - su contenido no es el pasado relegado al olvido por obra de la represión, sino el futuro que es preciso liberar de las trabas que puedan reprimirlo. Ése es el caso de los "sueños diurnos", esto es, de la imaginación que ejercitamos cuando decidimos que soñamos despiertos. Cuanto se acaba de decir reviste especial importancia desde un punto de vista ético, pues la ética - que Bloch ejemplifica en la ética kantiana - está para él siempre transida, aun cuando sea abstractamente, de lo que el propio Kant llamaba la "esperanza de futuro". Lejos de inducirnos al quietismo, la ética como utopía - la utopía éticanos puede seguir dando - incluso si la noche y la niebla de la disutopía han hecho desaparecer de nuestro campo de visión todo horizonte - más de una razón, tal vez las únicas razones, para no estarnos quietos ${ }^{38}$.

${ }^{36}$ Cf. Javier Muguerza, La razón sin esperanza, op. cit., p. 66.

37 Cf. op. cit., p. 65 .

38 Cf. Javier Muguerza, «Razón, utopía y disutopía», en Desde la perplejidad, op. cit., pp. 389 , 391 y 419 
Tengo para mí que, si alguien se aprestase a realizar un exhaustivo recorrido por toda su obra con esa intención, quizá le fuera relativamente sencillo recopilar distintos fragmentos del autor de La razón sin esperanza, para recomponer con ellos un libro que bien podría titularse La sinrazón de la esperanza. Dicho escrito debería verse firmado por Ernst-Immanuel-Javier Muguerza. $\mathrm{Y}$ en ese texto las tres célebres preguntas de Kant vendrían a reformularse más o menos así: 1) ¿hasta dónde pueden llegar los límites de nuestro lenguaje?; 2) ¿cuándo y cómo debemos disentir del consenso jurídico-moral establecido; 3 ) ¿qué nos cabe soñar utópicamente con respecto a un mañana mejor?

En suma, esas tres cuestiones quedarían ahora compendiadas en este interrogante: ¿qué podría llegar a ser el hombre, si se atuviese siempre a los dictados de su conciencia moral y fuera transformando con ellos el mundo en que le ha tocado vivir? 